\title{
pH-Responsive Near-Infrared Emitting Conjugated Polymer Nanoparticles for Cellular Imaging and Controlled-Drug Delivery
}

\author{
Jousheed Pennakalathil, ${ }^{1,2 *}$ Alp Özgün, ${ }^{2 *}$ Irem Durmaz, ${ }^{3}$ Rengül Cetin-Atalay, ${ }^{3}$ Dönüs Tuncel ${ }^{1,2}$ \\ ${ }^{1}$ Department of Chemistry, Bilkent University, 06800 Ankara, Turkey \\ ${ }^{2}$ National Nanotechnology Research Center, Institute of Material Science and Nanotechnology, Bilkent University, 06800 Ankara, Turkey \\ ${ }^{3}$ Department of Molecular Biology and Genetics, Bilkent University, 06800 Ankara, Turkey \\ Correspondence to: D. Tuncel (E-mail: dtuncel@fen.bilkent.edu.tr)
}

Received 2 September 2014; accepted 28 October 2014; published online 17 November 2014

DOI: $10.1002 /$ pola.27458

ABSTRACT: In this article, pH-responsive near-infrared emitting conjugated polymer nanoparticles (CPNs) are prepared, characterized, and their stabilities are investigated under various conditions. These nanoparticles have capacity to be loaded with water insoluble, anticancer drug, camptothecin (CPT), with around $10 \%$ drug loading efficiency. The in vitro release studies demonstrate that the release of CPTs from CPNs is $\mathrm{pH}$ dependent such that significantly faster drug release at mildly acidic $\mathrm{pH}$ of 5.0 compared with physiological $\mathrm{pH} 7.4$ is observed. Time and dose-dependent in vitro cytotoxicity tests of blank and CPT-loaded nanoparticles are performed by realtime cell electronic sensing (RT-CES) assay with hepatocellular carcinoma cells (Huh7). The results indicate that CPNs can be effectively utilized as vehicles for $\mathrm{pH}$-triggered release of anticancer drugs. (c) 2014 Wiley Periodicals, Inc. J. Polym. Sci., Part A: Polym. Chem. 2015, 53, 114-122

KEYWORDS: cellular imaging; conjugated polymers; drug delivery systems; luminescence; nanoparticles; near IR emission; $\mathrm{pH}$-responsive
INTRODUCTION The delivery of drugs by nanoparticle-based systems offers many advantages over conventional methods such as reduced systemic toxicity and enhanced drug efficiency on target could be achieved due to enhanced permeation and retention effect (EPR). ${ }^{1-3}$ Moreover, these systems can be designed to include multiple moieties such as active site targeting agents, imaging agents, immune evasion mechanisms, and microenvironment sensors for passive targeting at the cost of increased complexity and convoluted working mechanisms with each added moiety. ${ }^{4}$ Especially, polymeric nanoparticles are very appropriate for this purpose as their versatile surface chemistry can easily be adjusted for functionalizing with different moieties. ${ }^{5-7}$ Furthermore, their sizes can be tuned for different applications by changing simple parameters in the synthesis procedure. Most polymers tend to be biocompatible and show low toxicity due to their chemical inertness or they can be designed to degrade into harmless compounds in biological media. In addition, the microenvironment sensing properties such as $\mathrm{pH}$ sensitivity can be added to these polymers by making simple changes in the polymer structure. ${ }^{8-11}$ It is known from the literature that endosomes and tumour microenvironments have relatively acidic $\mathrm{pH}$ values. Once the drug-loaded nanoparticles are internalized by the cells, some of the endocytosed drug-loaded nanoparticles begin to hydrolyse under acidic environment in endosomes; this will, in turn, causes the swelling of nanoparticles and simultaneous delivery of drugs into the cytosol. ${ }^{12}$

Real-time biological imaging of the tumour site is one of the most important factors in cancer treatment. ${ }^{13,14}$ Moreover, combining therapeutic and imaging agents on a single system provides information about drug biodistribution and pathological processes which helps physicians to make more informed decisions on treatment strategies. To this end, there has been great interest to develop multifunctional nanoparticles which contain fluorescence imaging agents. ${ }^{15}$ For this purpose, small fluorescent dyes and fluorescent proteins are used as traditional fluorescent markers but they exhibit poor photostability as they fade away rapidly during imaging and this, in turn, limits their use in long term monitoring of live cells. ${ }^{16}$ Luminescent nanoparticles such as quantum dots and dye-loaded silica nanoparticles are found to be suitable for these purposes as these nanoparticles possess high brightness and photostability compared with small fluorescent dyes. However, their cytotoxicity is considered as a serious problem for their in vivo applications because of

*Jousheed Pennakalathil and Alp Özgün contributed equally to this work

Additional Supporting Information may be found in the online version of this article.

(c) 2014 Wiley Periodicals, Inc. 
the presence of toxic heavy metals (e.g. Cd). ${ }^{17}$ Dye-loaded silica nanoparticles also present some drawbacks; only limited amount of dyes can be loaded due to $\pi-\pi$ interaction between the dye molecules which causes a reduced fluorescent quantum yields. ${ }^{18}$

An emerging alternative is the use of conjugated polymer particles as fluorescent labels because of their high quantum yields, high molar absorptivity, photo stability, and easy synthesis. ${ }^{19-31}$ However, there is not much research on the metabolic processes of these nanoparticles. In the in vivo studies, the biodistribution profile of these nanoparticles after $72 \mathrm{~h}$ postinjection showed uptake in the tumorous tissue as well as liver and the spleen indicating that they could be cleared out from the body through liver. ${ }^{32}$ Although the use of conjugated polymer nanoparticles for dual delivery of therapeutic agents and cell imaging offers many advantages, this strategy is largely unexplored and there are few reports relating to this concept. ${ }^{33-38}$ For instance, the inherent fluorescence of the conjugated polymers could eliminate the need for an imaging agent in the designed delivery vehicle thus making the system less complicated. There are many examples in the literature on the pH-responsive polymeric nanoparticles designed for the delivery of drugs; ${ }^{8,9,39}$ however, to the best of our knowledge, examples are scarce on the drug delivery system which is based on pH-responsive near-infrared emitting conjugated polymer nanoparticles. Recently we have reported on the red emitting $\mathrm{pH}$ responsive conjugated oligomer-based nanoparticles for drug delivery and cellular imaging. ${ }^{40}$ Although these conjugated oligomer-based nanoparticles have many interesting features, they emit in the far red region and exhibit relatively low drug-loading efficiency (5.9\%) which needs further improvement. In this context, we report here novel, $\mathrm{pH}$-responsive, near-infrared emitting conjugated polymer nanoparticles with higher drug loading efficiency than oligomer-based nanoparticles for cellular imaging and controlled-drug release. These nanoparticles emit in the near-infrared region; have good photostability and low toxicity that are essentials for biological imaging. Near-infrared emission is highly desirable for bioimaging because it will enable high contrast in vivo imaging due to the lack of interference from tissue autofluorescence in the NIR window. ${ }^{41-43}$ In addition, due to the pH-sensitive pendant groups on the polymer chains, nanoparticles formed from these polymers are sensitive to lower $\mathrm{pH}$ levels found in most tumour microenvironments offering a promise for use in chemotherapeutic drug delivery applications.

\section{EXPERIMENTAL}

\section{General}

All solvents and reagents including, 2-(thiophen-3-yl)ethanol, 2,1,3-benzothiadiazole-4,7-bis(boronic acid pinacol ester), $\mathrm{N}$ bromosuccinimide, tetrabutylammonium bromide, bromobenzene, tetrakis(triphenylphosphine)palladium, were purchased from Sigma-Aldrich Chemical Co. and were used as received. ${ }^{1} \mathrm{H}$ and ${ }^{13} \mathrm{C}$ NMR spectra recorded on a Bruker
Avance III $400 \mathrm{MHz}$ spectrometer using $\mathrm{CDCl}_{3}$ as a solvent. FT-IR measurements recorded on a Bruker TENSOR 27. Samples were prepared as a $\mathrm{KBr}$ pellet. For optical characterization, a UV-Vis spectrophotometer (Cary UV-Vis) and a fluorescence spectrophotometer (Cary Eclipse Fluorescent spectrophotometer) equipped with a xenon-lamp as the excitation source were used. The molecular weight of the polymer P1 was determined using gel permeation chromatography (GPC) on Polymer Laboratories PL-GPC220 system equipped with a RI detector in THF using a calibration curve of polystyrene standards.

Nanoparticles sizes were measured by dynamic light scattering (DLS, Zetasizer Nano-ZS). Measurements were carried out at $633 \mathrm{~nm}$ and the laser, as a light source, was used at room temperature. Morphological characterization was done by scanning electron microscopy (SEM, Quanta 200 FEG SEM) and transmission electron microscopy (TEM, FEI Tecnai G2 F30). The DLS measurements were usually repeated at least three times and the average values were reported.

\section{2-(2,5-Dibromothiophen-3-yl)ethyl acetate (M2)}

2-(2,5-dibromothiophen-3-yl)ethanol (M1) was synthesized according to literature procedure. ${ }^{22}$ A stirred solution of M1 (1.00 g, $3.50 \mathrm{mmol})$ in $10 \mathrm{~mL}$ acetic anhydride was added pyridine ( $400 \mu \mathrm{L}, 5.24 \mathrm{mmol}$,) and the reaction mixture was allowed to stir at room temperature for overnight. After the reaction was over, the mixture was diluted with DCM; water was added and the extraction was carried out. Organic phase was collected and washed with water several times. The solvent was evaporated under reduced pressure which provided pale yellow liquid. This was further stirred with $20 \mathrm{~mL} \mathrm{MeOH}$ for $20 \mathrm{~min}$ to convert the remaining acidanhydride into methylester which was easily evaporated under reduced pressure. Product was purified by Si-gel column chromatography using cyclohexane as an eluent (1.04 g, 90\%).

${ }^{1} \mathrm{H}-\mathrm{NMR}\left(400 \mathrm{MHz}, \mathrm{CDCl}_{3}, 25{ }^{\circ} \mathrm{C}\right): \delta 6.85(\mathrm{~s}, 1 \mathrm{H}, \mathrm{c}), 4.25(\mathrm{t}$, $\left.{ }^{3} J=6.4 \mathrm{~Hz}, 2 \mathrm{H}, \mathrm{a}\right), 2.82\left(\mathrm{t},{ }^{3} \mathrm{~J}=6.4 \mathrm{~Hz}, 2 \mathrm{H}, \mathrm{b}\right), 2.05(\mathrm{~s}, 3 \mathrm{H}, \mathrm{d})$; ${ }^{13} \mathrm{C}$-NMR $\left(100 \mathrm{MHz}, \mathrm{CDCl}_{3}, 25{ }^{\circ} \mathrm{C}\right): \delta 20.9,28.9,62.9,109.7$, $110.9,131.0,138.3,170.7$. HRMS (ESI) calcd. for $[\mathrm{M}+\mathrm{K}-2 \mathrm{H}]^{-}$ $\left(\mathrm{C}_{8} \mathrm{H}_{6} \mathrm{Br}_{2} \mathrm{KO}_{2} \mathrm{~S}\right)$ 362.8087, found 362.8006 .

\section{Synthesis of Poly [2-(2,5-dibromo-thiophen-3-yl)-ethyl acetate)-co-4,7-(2,1,3-benzothiadiazole)] (P1)}

2-(2,5-dibromo-thiophen-3-yl)-ethyl acetate (515.4 mg, 1.581 mmol) and 2,1,3-benzothiadiazole-4,7-bis(boronic acid pinacol ester) (613.9 mg, $1.581 \mathrm{mmol}$ ) were placed into a twonecked RBF. The mixture was left under vacuum for $20 \mathrm{~min}$. Degassed THF (20 mL) was added and stirred for $10 \mathrm{~min}$. Then the aqueous solution of $\mathrm{K}_{2} \mathrm{CO}_{3}(1500 \mathrm{mg}, 7.905 \mathrm{mmol})$ in $10 \mathrm{~mL}$ degassed water was added, TBAB (50 mg) was added and the reaction was stirred for $10 \mathrm{~min}$. Then the mixture was degassed via two cycles of freeze-pump-thaw and the flask was filled with $\mathrm{N}_{2}$ gas. $\mathrm{Pd}\left(\mathrm{PPh}_{3}\right)_{4}(91 \mathrm{mg}$, $0.079 \mathrm{mmol}$ ) was added quickly. The mixture was heated to $80{ }^{\circ} \mathrm{C}$ under $\mathrm{N}_{2}$ gas $16 \mathrm{~h}$. Twenty milliliters degassed THF and $10 \mathrm{~mL}$ degassed toluene were added. The mixture was 


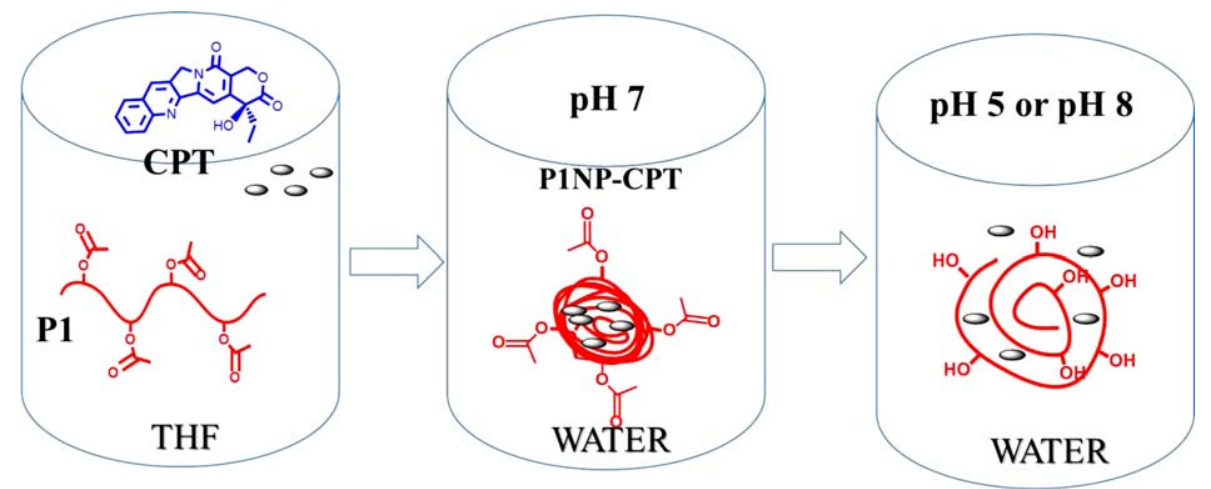

SCHEME 1 An overview of the preparation of drug-loaded nanoparticles and pH-triggered drug release mechanism of the nanoparticles. [Color figure can be viewed in the online issue, which is available at wileyonlinelibrary.com.]

further stirred under $\mathrm{N}_{2}$. A purple colour solution was obtained. After about $66 \mathrm{~h}$ bromobenzene $(100 \mu \mathrm{L})$ was added and the reaction was further heated $4 \mathrm{~h}$ more. After the completion of the reaction, the solvents were removed under reduced pressure and the residue was washed with water several times. Then the precipitate was filtered, washed with $\mathrm{MeOH}$. The crude product was redissolved in $\mathrm{THF}$ and precipitated into cold $\mathrm{MeOH}$ for further purification. Purple coloured powder was collected and dried under vacuum for $5 \mathrm{~h}$ (525 mg, 46\%).

${ }^{1} \mathrm{H}-\mathrm{NMR}\left(400 \mathrm{MHz}, \mathrm{CDCl}_{3}, 25^{\circ} \mathrm{C}\right): \delta: 2.05(\mathrm{~m}, 3 \mathrm{H}), 3.15(\mathrm{~m}$, 2H), $4.4(\mathrm{~m}, 2 \mathrm{H}), 7.1(\mathrm{~m}, 1 \mathrm{H}), 7.9-8.2(\mathrm{~m}, 2 \mathrm{H}) ;{ }^{13} \mathrm{C}-\mathrm{NMR}$ $\left(100 \mathrm{MHz}, \mathrm{CDCl}_{3}, 25{ }^{\circ} \mathrm{C}\right): \delta 21.0,29.1,29.9,64.2,125.2$, $125.6,130.1,130.4,152.3,152.6,170.9$.

GPC: $M_{\mathrm{n}}=2.5 \times 10^{4} \mathrm{~g} \mathrm{~mol}^{-1}, M_{\mathrm{w}}=5.2 \times 10^{4} \mathrm{~g} \mathrm{~mol}^{-1}(\mathrm{THF}$ as a solvent and polystyrene as standard).

\section{Preparation of Nanoparticles of P1}

In a typical procedure, P1 (1.0 mg, $3.3 \times 10^{-3} \mathrm{mmol}$, based on per repeating unit) was dissolved in dry THF (1 mL). The solution was sonicated for $\sim 15 \mathrm{~min}$ and then injected rapidly to $20 \mathrm{~mL}$ of DD water. The sonication was continued for a further $30 \mathrm{~min}$. THF was removed from the solution under reduced pressure.

\section{RESULTS AND DISCUSSION}

\section{Synthesis and Characterization of Polymer P1}

For the preparation of $\mathrm{pH}$-responsive and near-infrared emitting nanoparticles, polymer 1 (Scheme 2) (P1) was designed by taking the following points into consideration: P1 is hydrophobic at neutral $\mathrm{pH}$ but can be made hydrophilic at low and high $\mathrm{pH}$ values by hydrolysing the acetyl groups to hydrophilic hydroxyl groups. Thus, it would be easier to form nanoparticles and drug-loaded nanoparticles from hydrophobic polymer P1; since the nanoparticles will have more compact shapes at neutral $\mathrm{pH}$ and hold the drugs tightly but at low or high $\mathrm{pH}$ values due to hydrolysis, the nanoparticles will swell and the polymer chains will be loosely folded because of the interaction of hydroxyl groups with water. This, in turn, will trigger the release of drugs from the nanoparticles (Scheme 1). Besides, P1 itself is selfluminescent and emits in the near infrared region of the spectrum.

This feature offers several advantages such as eliminating the need for an extra fluorophore in the system for cellular imaging and the drugs will be encapsulated in high loading rate because of the favourable interactions with polymer aromatic backbone.

Polymer 1 was synthesized according to the reaction Scheme 2. First 2-(thiophen-3-yl)ethanol was brominated using $N$ bromosuccinimide in ethyl acetate to obtain 2-(2,5-dibromothiophen-3-yl)ethanol ${ }^{18 d}$ (M1) and then its hydroxyl group was acetylated using acetic acid anhydride to yield the target monomer (M2). Suzuki Coupling of M2 and 1,2,3-benzothiadiazole-4,7-bis(boronic acid pinocol ester) afforded polymer $\mathrm{P} 1$ in $46 \%$ yield as purple powders.

Structural characterization of polymer was carried out via ${ }^{1} \mathrm{H}$ and ${ }^{13} \mathrm{C}$ NMR (Supporting Information Fig. S3) and FT-IR

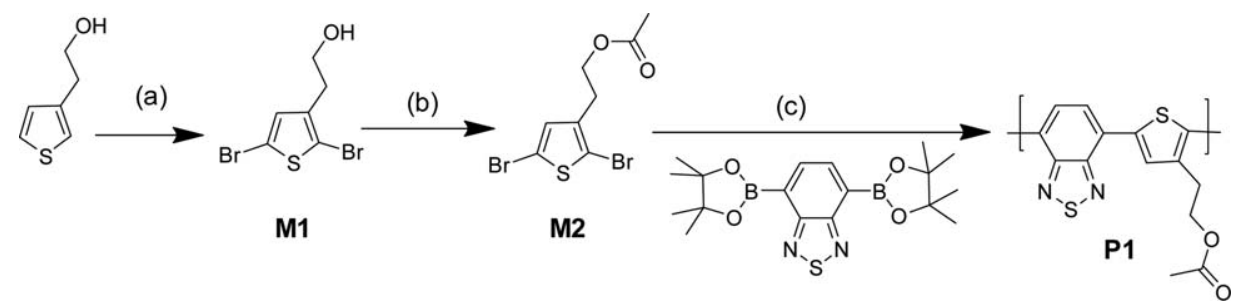

SCHEME 2 Reaction scheme for P1. (a) 2-(thiophen-3-yl)ethanol, NBS, EtOAc, $25{ }^{\circ} \mathrm{C}, 12 \mathrm{~h}, 60 \%$; (b) acetic anhydride, pyridine, 25 ${ }^{\circ} \mathrm{C}, 12 \mathrm{~h}, 90 \%$; (c) $\mathrm{THF} /$ toluene/ $\mathrm{H}_{2} \mathrm{O}(1: 1: 1, \mathrm{v} / \mathrm{v}), \mathrm{K}_{2} \mathrm{CO}_{3}$ (aq.), $\mathrm{TBAB}, \mathrm{Pd}\left(\mathrm{PPh}_{3}\right)_{4}, 80{ }^{\circ} \mathrm{C}, 72 \mathrm{~h}, 46 \%$. 


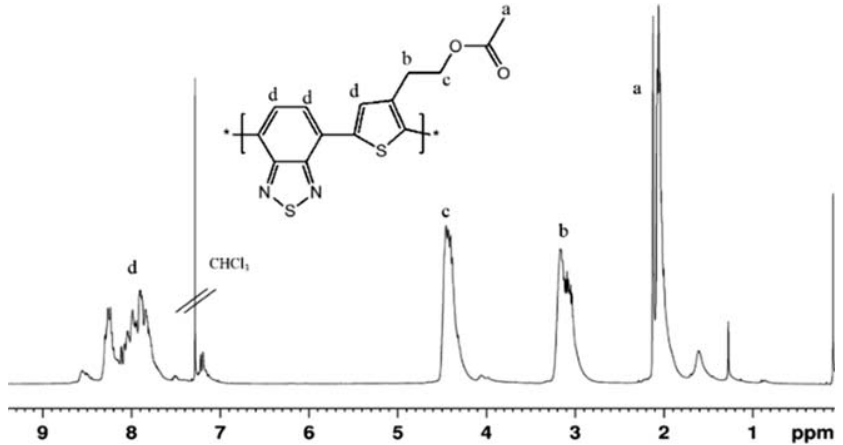

FIGURE $1{ }^{1} \mathrm{H}-\mathrm{NMR}\left(400 \mathrm{MHz}, \mathrm{CDCl}_{3}, 25^{\circ} \mathrm{C}\right)$ spectrum of $\mathrm{P} 1$.

spectroscopies. Figure 1 show the ${ }^{1} \mathrm{H}-\mathrm{NMR}$ spectrum of P1 which confirms the expected structures of the polymer. In the FT-IR spectrum of P1 (Supporting Information Fig. S5), the presence of the characteristic carbonyl stretching at around $1700 \mathrm{~cm}^{-1}$ supports further the expected structure of the polymer.

The molecular weight of polymer was determined by GPC (Supporting Information Fig. S6). $M_{\mathrm{n}}$ and $M_{\mathrm{w}}$ values of P1 have been found to be as $25 \mathrm{kDa}$ and $52 \mathrm{kDa}$, respectively, with polydispersity index (PDI) of 2.1 which is in an expected range for a step-growth polymerization.

\section{Synthesis of Nanoparticles and Investigation of their Stabilities}

Nanoparticles were prepared by a simple reprecipitation method as reported in the literature. ${ }^{37}$ Briefly, polymer solution in THF is injected into a large excess of water under sonication and by the removal of the THF under reduced pressure, stable nanoparticles are obtained. It is possible to tune the sizes of nanoparticles by varying the concentration of polymers used. Here we used different concentrations of polymer to demonstrate the effect of polymer concentrations on the nanoparticle sizes. The results confirm that the structures and the concentrations of the polymers directly affect

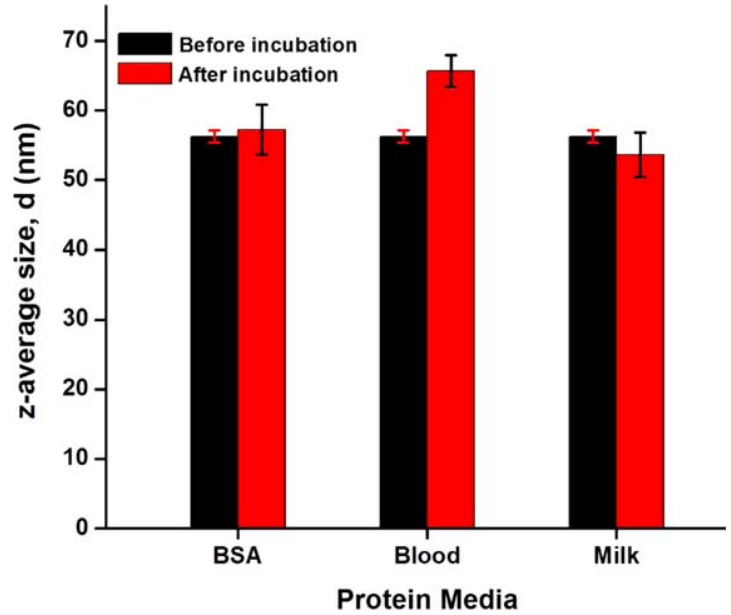

FIGURE 3 The nanoparticles in different protein environments such as bovine serum albumin (BSA), human serum, and milk to test their stabilities. [Color figure can be viewed in the online issue, which is available at wileyonlinelibrary.com.]

the size of nanoparticles; an increase in the polymer concentration causes an increase in the size of the nanoparticles.

All details involving the synthesis of the nanoparticle with varying concentration were provided in the Supporting Information section (Supporting Information Tables S1 and S2, Figs. S7 and S8). Nanoparticles with average size $56 \mathrm{~nm}$ have been selected to be used throughout of this article with the final polymer concentration of $0.5 \mathrm{mg} / \mathrm{mL}$ (in water). Figure 2 shows SEM (a), TEM (b) microscope images and DLS (c), zeta potential (d) histograms of NP-P1 with average size $56 \mathrm{~nm}$.

In order to test the stability of P1NPs in water and PBS buffer (at pH 7.4), DLS measurements were taken over 35 days. The measurement results clearly show that there are no significant changes in the initial size of the nanoparticles confirming that these nanoparticles are stable in water and PBS buffer for prolonged time (Supporting Information Fig. S9).
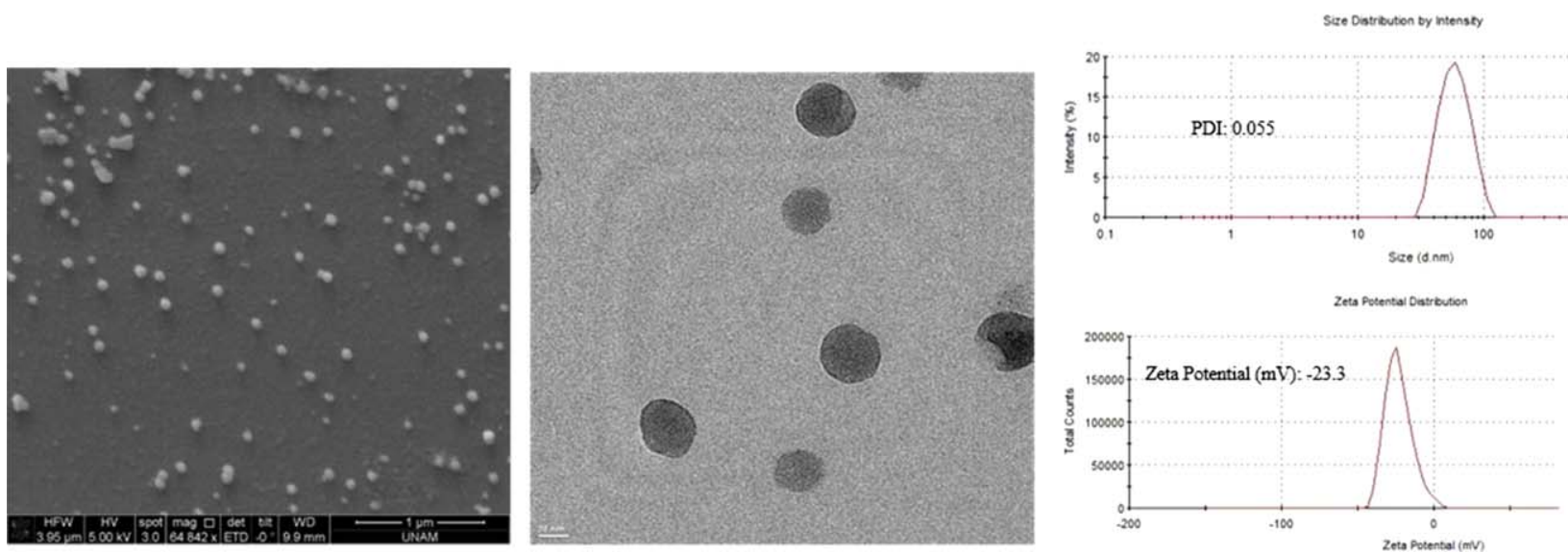

FIGURE 2 SEM (a), TEM (b) microscope images and DLS, zeta potential histograms of NP-P1. [Color figure can be viewed in the online issue, which is available at wileyonlinelibrary.com.] 

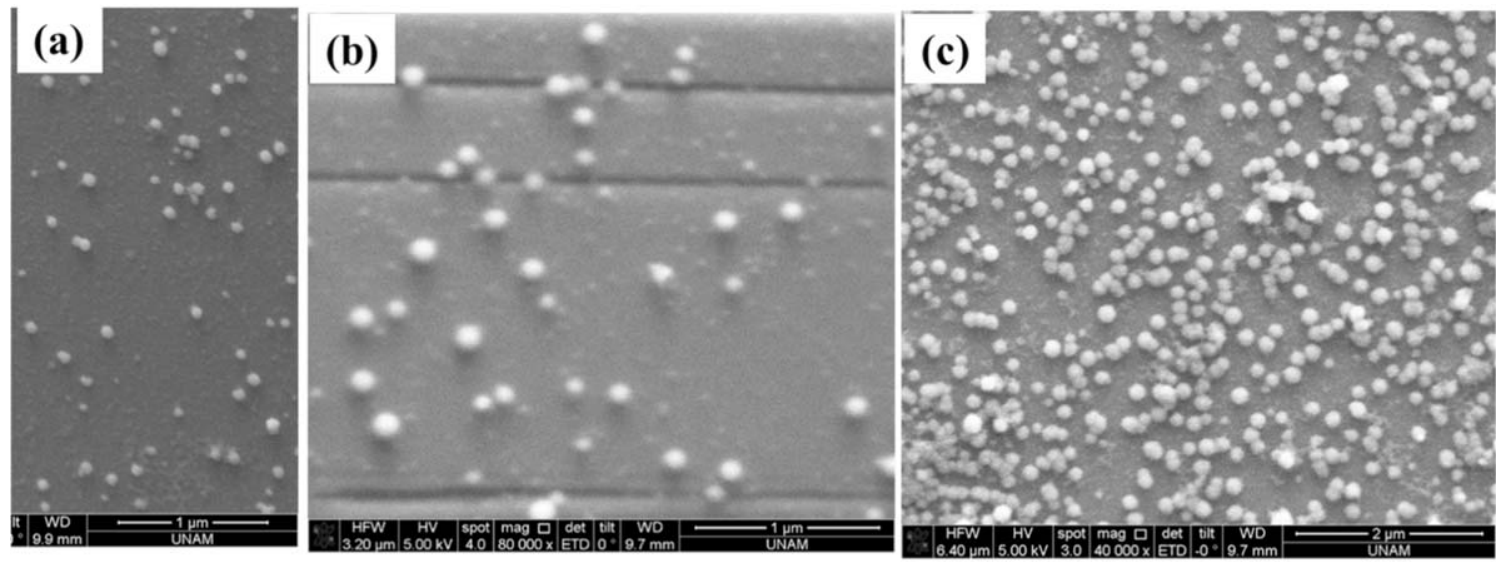

(d)

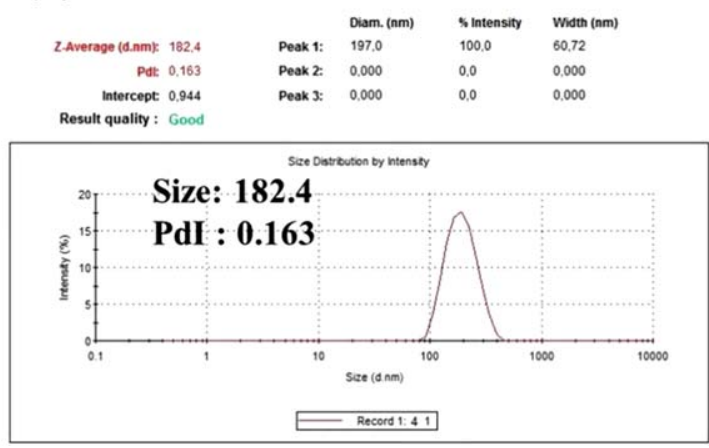

(e)

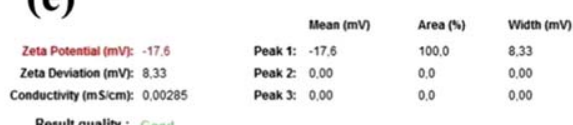

Result quality : Good

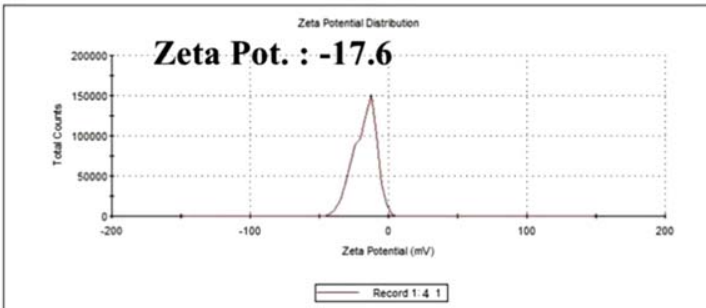

FIGURE 4 SEM images of NP-P1, (a) initial state (scale $1 \mu \mathrm{m}$ ), (b) after $4 \mathrm{~h}$ exposure of pH 5 (scale $1 \mu \mathrm{m}$ ), (c) after $4 \mathrm{~h}$ exposure of pH 5 (scale $2 \mu \mathrm{m}),(\mathrm{d})$ DLS, zeta potential histograms of NP-P1 after $4 \mathrm{~h}$ exposure of $\mathrm{pH}$. [Color figure can be viewed in the online issue, which is available at wileyonlinelibrary.com.]

Next, we incubated P1NPs in different protein environments such as bovine serum albumin (BSA), milk, and human serum to test their stabilities. The changes in the size of nanoparticles are insignificant in both BSA and milk media (Fig. 3). But there is around $10 \mathrm{~nm}$ increase in the incubation with human serum. This may be due to weak nonspecific interactions of nanoparticles with some of the proteins in the mixture.

The nanoparticles were further exposed to buffered aqueous solutions of $\mathrm{pH} 5.0$ or 8.0 and their average sizes and zeta potential values were recorded at regular intervals (Supporting Information Figs. S10-S12). The size of the nanoparticles exposed to $\mathrm{pH} 5.0$, was gradually increased from the initial size of $56 \mathrm{~nm}$ to $180 \mathrm{~nm}$ around $4 \mathrm{~h}$ and not much change was observed even after $24 \mathrm{~h}$. The initial zeta potential value of -23 changed to $-18 \mathrm{mV}$. SEM image of the nanoparticles showed the presence of spherical nanoparticles with about $180 \mathrm{~nm}$ average size (Fig. 4). Similar results were obtained with nanoparticles exposed to $\mathrm{pH} 8$; however, in this case the initial size of nanoparticles increased from $56 \mathrm{~nm}$ to over $200 \mathrm{~nm}$ even in $1 \mathrm{~h}$ with zeta potential value of -24 (Supporting Information Fig. S12).

Although P1 is not a conventional pH-sensitive polymer which contain carboxylic or amine groups, still the size changes in the nanoparticles can be explained by the $\mathrm{pH}$ responsiveness of the polymer 1 . P1 contains acetyl groups which can be hydrolyzed by acid or base. Consequently, the nature of the polymer could be switched from hydrophobic to hydrophilic by hydrolyzing acetyl group to hydroxyl group. In this way, nanoparticles made from acetyl group carrying polymer will exhibit hydrophobic character and have a rather compact shape, however, by the hydrolysis of acetyl groups to hydroxyl groups polymer chains will be loosely held because of the interaction of hydroxyl groups with water and the nanoparticles become larger.

Similar approach was reported by Griset et al. ${ }^{44,45}$ In their work, first hydroxyl groups of the polymer used were protected as acetal to obtain a hydrophobic polymer which was utilized to prepare cross-linked nanoparticles. When these nanoparticles were exposed to $\mathrm{pH} 5$, acetal groups were hydrolyzed to reveal hydroxyl groups and because of the interaction of hydroxyl groups with water the nanoparticles expanded 3 to 10 folds of their initial size. Although in our case the nanoparticles were not cross-linked, still they were not completely disintegrated into polymer chains after the hydrolysis due to the presence of a large hydrophobic polymer backbone which helps keeping them intact.

The faster size increase in shorter duration at $\mathrm{pH} \mathrm{8,} \mathrm{com-}$ pared with $\mathrm{pH} 5$ indicates that acetyl groups are hydrolyzed faster at $\mathrm{pH} 8$ than $\mathrm{pH}$ 5. To prove further hydrolysis is 
TABLE 1 Optical Properties of Polymer in Different Solvents, Dispersion of Polymer Nanoparticles in Water, in Acetate Buffer ( $\mathrm{pH}$ 5.0), and Polymer Film

\begin{tabular}{lllll}
\hline Solvent & $\lambda_{\text {abs }}(\mathrm{nm})$ & $\lambda_{\mathrm{em}}(\mathrm{nm})$ & $\Phi_{\mathrm{f}}{ }^{\mathrm{a}}(\%)$ & $\varepsilon^{\mathrm{b}}\left(\mathrm{cm}^{-1} \mathrm{M}^{-1}\right)$ \\
Chloroform & 505 & 620 & 47.4 & 25,878 \\
THF & 510 & 627 & 31.9 & 21,813 \\
DMF & 515 & $640,700(\mathrm{sh})$ & 17.3 & 12,119 \\
Water & 530 & 717 & 2.3 & 6902 \\
Acetate buffer & 530 & 717 & 3.0 & 7243 \\
In film & 544 & 731 & n.d. & n.d.
\end{tabular}

${ }^{a}$ Fluorescent quantum yields are calculated using Rhodamine B in ethanol as standard ( $\Phi_{\mathrm{f}}: 98 \%$ ).

${ }^{\mathrm{b}}$ Molar absorptivity per repeat unit.

n.d.: not determined; sh: shoulder.

taking place, $\mathrm{pH} 5$ and $\mathrm{pH} 8$ treated nanoparticle dispersions were centrifuged to obtain precipitate which was redispersed in water and centrifugation was repeated to remove buffer residues. The collected precipitate was characterized by FT-IR spectrometer. FT-IR spectra of both samples show that the peak around $1700 \mathrm{~cm}^{-1}$ due to the carbonyl stretching of acetyl groups has disappeared indicating the hydrolysis of acetyl groups (Supporting Information Fig. S13).

\section{Optical Properties of Polymer P1 and Nanoparticles}

The optical properties of the nanoparticles were investigated by UV-Vis and fluorescence spectroscopy and compared with the polymers in different solvents and film; the results are tabulated in the Table 1.

Bathochromic shifts were observed in the absorption and emission spectra of the polymer P1 upon increasing the polarity of solvent (Supporting Information, Fig. S14) implying that the polymer has solvatochromic properties. ${ }^{46}$ However, upon converting the polymer into nanoparticles larger bathochromic shifts are observed in the emission peaks which show similarities with the absorption and emission spectra of the polymer in film (the spectrum is provided in Supporting Information, Fig. S15). This suggests that the bathochromic shifts are not only due to solvent effect but also due to the intra and intermolecular interactions of polymer chains caused by tight folding.

\section{Drug Loading Study of Polymer Nanoparticles}

Camptothecin-loaded nanoparticles have been prepared in a single step synthesis. Briefly, polymers and CPT are dissolved in THF and injected into water while stirring under sonication. After the removal of THF, the dispersion of nanoparticles in water is obtained. In order to determine the loading and entrapment efficiency of the nanoparticles, ratios of CPT to polymers (w/w) 1:0.5, 1:1, 1:2, 1:6.25, 1:12.5, and 1:25 were used during the nanoparticle preparation. In each case, after the nanoparticle formation, the dispersion was dialyzed against water using a 14 $\mathrm{kDa}$ MWCO regenerated cellulose membrane for $24 \mathrm{~h}$ to remove any remaining unencapsulated CPT. The dialysates were analyzed by recording their absorption spectra $\left(\lambda_{\max }=366 \mathrm{~nm}\right)$ and the unencapsulated CPT concentration was calculated from a calibration curve of CPT plotted from known concentrations of CPT solutions. The lowest detectable concentration in water was $25.4 \mathrm{nM}$ which shows that our method allows us to detect less than $8 \%$ of CPT in the set with the lowest CPT concentration. The measurements taken from the dialysate of free CPT showed the same absorbance with the corresponding concentration of CPT suspension in water containing Tween $20(0.2 \%, \mathrm{v} /$ v) $24 \mathrm{~h}$ later. This shows that a $24 \mathrm{~h}$-period is long enough for unentrapped CPT to homogenously disperse into medium. The entrapment efficiency (EE) and loading efficiency (LE) were calculated according to the following equations and the results are presented in Figure 5.

$$
\begin{aligned}
& \mathrm{EE}=\text { loaded drug wt./total drug wt. } \times 100 \\
& \mathrm{LE}=\text { loaded drug wt./total system wt. } \times 100
\end{aligned}
$$

The set with the lowest CPT concentration (drug:polymer ratio of $1: 25$ ) shows a $40 \%$ entrapment rate with the loading efficiency of $1.6 \%$. As CPT concentration increases, loading efficiency increases up to around $9.8 \%$ and entrapment efficiency reaches a plateau value of $63 \%$ at the drug to polymer ratio of $1: 6.25$.

The synthesis of CPT-loaded CPNs was repeated more than three times by keeping the synthetic conditions constant. Their size was determined by dynamic light scattering (DLS) measurements and the results are tabulated in the Supporting Information Table S5. As it can be seen from the DLS measurements, the size of the drug loaded nanoparticles are dependent on the drug loading contents as there is a linear increase in the size of nanoparticles with increasing drug contents. However, the changes are not huge indicating that the structural integrity of the nanoparticles is not affected when they are loaded with drug. The reason could also be attributed to the $\pi-\pi$ interactions between the aromatic conjugated backbone of the polymer chains and the aromatic rings of the CPT molecules, causing a close packing of the drug molecules. ${ }^{37}$

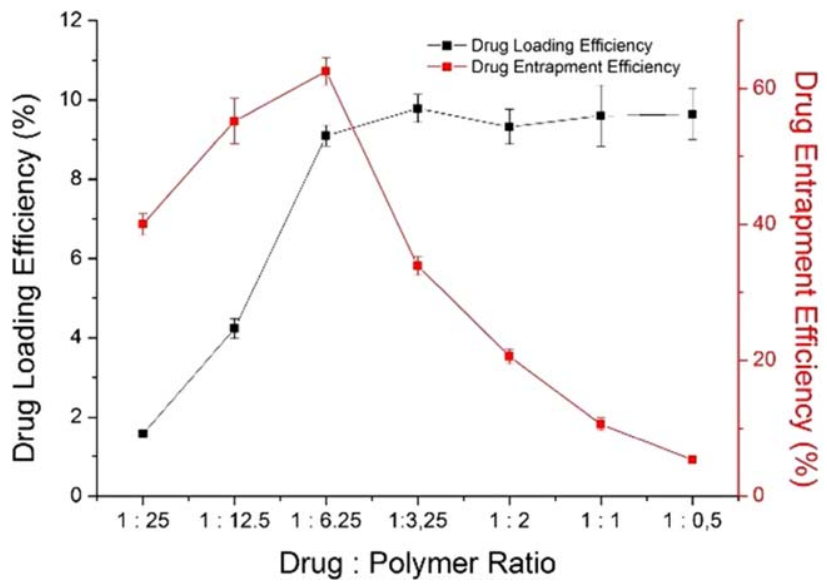

FIGURE 5 Drug loading and entrapment efficiencies. [Color figure can be viewed in the online issue, which is available at wileyonlinelibrary.com.] 


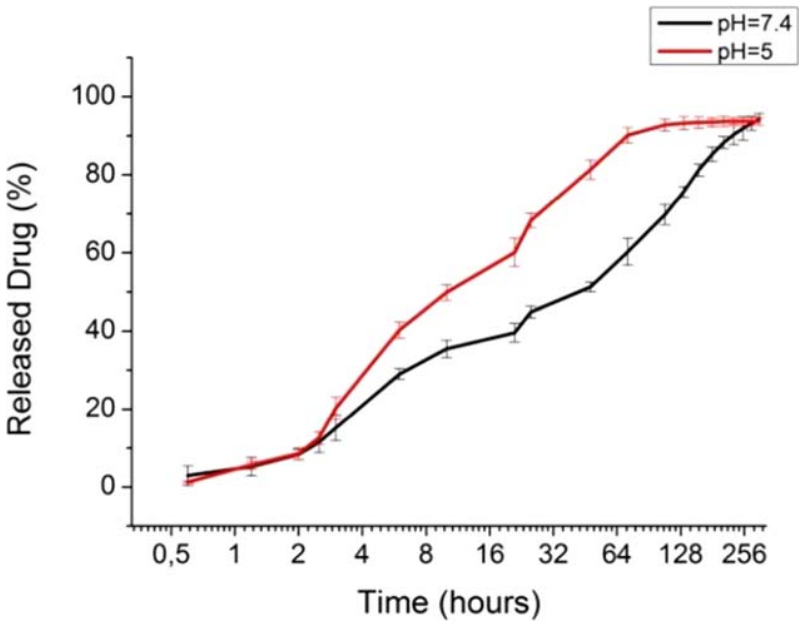

FIGURE 6 Percentage of cumulative release of CPT from NP1 at different $\mathrm{pH}$. The release of drug molecules was monitored using a UV-Vis spectrophotometer (1:10 loading ratio of CPT/ $\mathrm{P} 1 \mathrm{NP}$ ). [Color figure can be viewed in the online issue, which is available at wileyonlinelibrary.com.]

\section{In Vitro Drug Release Study of Nanoparticles}

The in vitro drug release studies of the nanoparticles with two different CPT contents as the CPT to P1NP ratios of 1:23 and 1:10 (determined after dialysis) were carried out at 37 ${ }^{\circ} \mathrm{C}$ at pH 5.0 (acetate buffer) and pH 7.4 (PBS). The timedependent release profiles of CPT from the nanoparticles were measured by the absorption at $366 \mathrm{~nm}$ with UV-Vis spectrophotometry. Figure 6 shows the release profile of CPT loaded P1NPs (CPT to P1NP ratio of 1:10).

In the case of nanoparticles with high drug loading content, around $50 \%$ of drugs were released from P1NPs at $\mathrm{pH} 5.0$ in the initial $12 \mathrm{~h}$, and the release was sustained over $110 \mathrm{~h}$, however, $90 \%$ of drugs have already released during $64 \mathrm{~h}$. On the other hand, the release was slower in pH 7.4 compared with $\mathrm{pH} 5.0$. Only $50 \%$ of the drugs were released around $48 \mathrm{~h}$ and $90 \%$ drug release reached to $256 \mathrm{~h}$. The release of drugs from nanoparticles with low drug loading content was observed to be slightly faster at both pHs than the former case (Supporting Information Fig. S18); the reason could be due to $\pi-\pi$ intermolecular interactions between the CPT molecules in high loading of nanoparticles which prevents the release of drugs.

The in vitro release studies demonstrated that the release of CPTs from NP1 were pH-dependent such that significantly faster drug release at mildly acidic $\mathrm{pH}$ of 5.0 (90\% during $64 \mathrm{~h}$ ) compared with physiological pH 7.4 (90\% during 256 h) was observed. The above results indicated NP1 are appropriate vehicles for $\mathrm{pH}$-triggered release of anticancer drugs.

\section{In Vitro Cell Assays}

Time and dose dependent in vitro cytotoxicity tests of blank and CPT-loaded nanoparticles (P1NPs) were performed by real-time cell electronic sensing (RT-CES) ${ }^{47,48}$ assay with hepatocellular carcinoma cells (Huh7) over the course of
144 h. RT-CES experiments involve using a gold plate and the system relies on electrical impedance cell sensors arrays embedded at the bottom of the plates. In this experiment we have tested the cytotoxicities of P1NPs as well as CPT-loaded nanoparticles in two different drug loading contents. These nanoparticles were abbreviated as P1NP-A-CPT and P1NP-BCPT which denote 1:62 and 1:10.4 (after dialysis), CPT/NP ratios, respectively. Free CPT was used as a positive control and DMSO and blank P1NPs were used as negative controls to the CPT-loaded P1NPs. Figure 7 shows the RT-CES assay results after the incubation of Huh7 cells with CPT, P1NPs blank, P1NP-A-CPT and P1NP-B-CPT over $144 \mathrm{~h}$ incubation period. Full experimental results were given in the Supporting Information Figure S17 and Table S6.

Blank nanoparticles at high concentrations (24.8 and $12.8 \mu \mathrm{M})$ appear to cause some changes in the cell behavior after $24 \mathrm{~h}$ incubation, growth inhibition reach to plateau values of 38 and $20 \%$, for the nanoparticle concentrations of 24.8 and $12.8 \mu \mathrm{M}$, respectively, at $72 \mathrm{~h}$ and then the inhibition rate decreases rapidly and the cells starts to be responsive again and proliferate. This behavior may suggest the complex, dynamic nature of the interaction between the cells and nanoparticles. This could also be explained by an incidental enzyme interaction in which the NPs could randomly bind on some proteins to inhibit their activities, however, the cell signaling pathways get involved at this stage by increasing the expression of proteins to compensate the initial inhibition. As a result, this will cause no serious harm to the cells to go to apoptosis but only a temporary inhibition in the cell growth process.

If we investigate the behaviors of CPT and CPT delivered by nanoparticles with different concentrations, CPT as we observed in our previous study, ${ }^{37}$ becomes rapidly effective in the cell growth inhibition even at the lowest concentration $(0.1 \mu \mathrm{M})$ and shorter time (48 h). However, in both concentrations the growth inhibition is slower than free CPT confirming the slow release feature of the nanoparticles supported by in vitro drug release studies in different $\mathrm{pHs}$. The release is even much slower in the case of the nanoparticles having high drug loading contents. This result might be explained by strong interactions between CPT molecules and polymer chains because CPT molecules can interact with each other more freely due to presence of fewer polymer chains to interfere with this process. In lower loading rates, CPT molecules can be evenly distributed in the polymer matrix; not unlike dissolution. Upon cell internalization, these matrices interact with hydrophobic membrane structures (endosomes) and CPT molecules can easily diffuse into these membranes to show activity in the cell. However, higher CPT content can bring out the intrinsic solubility problem of hydrophobic drugs. CPT molecules can easily form highly stable aggregates via $\pi-\pi$ stacking inside the sparsely packed matrix and their likelihood of interacting with cellular hydrophobic compartments drops drastically. Therefore they show little to no cellular activity for a long time after cell internalization.

CPT-loaded P1NPs were analyzed by fluorescence microscopy on Huh7 cells. The red emission of P1NPs is an evidence for 

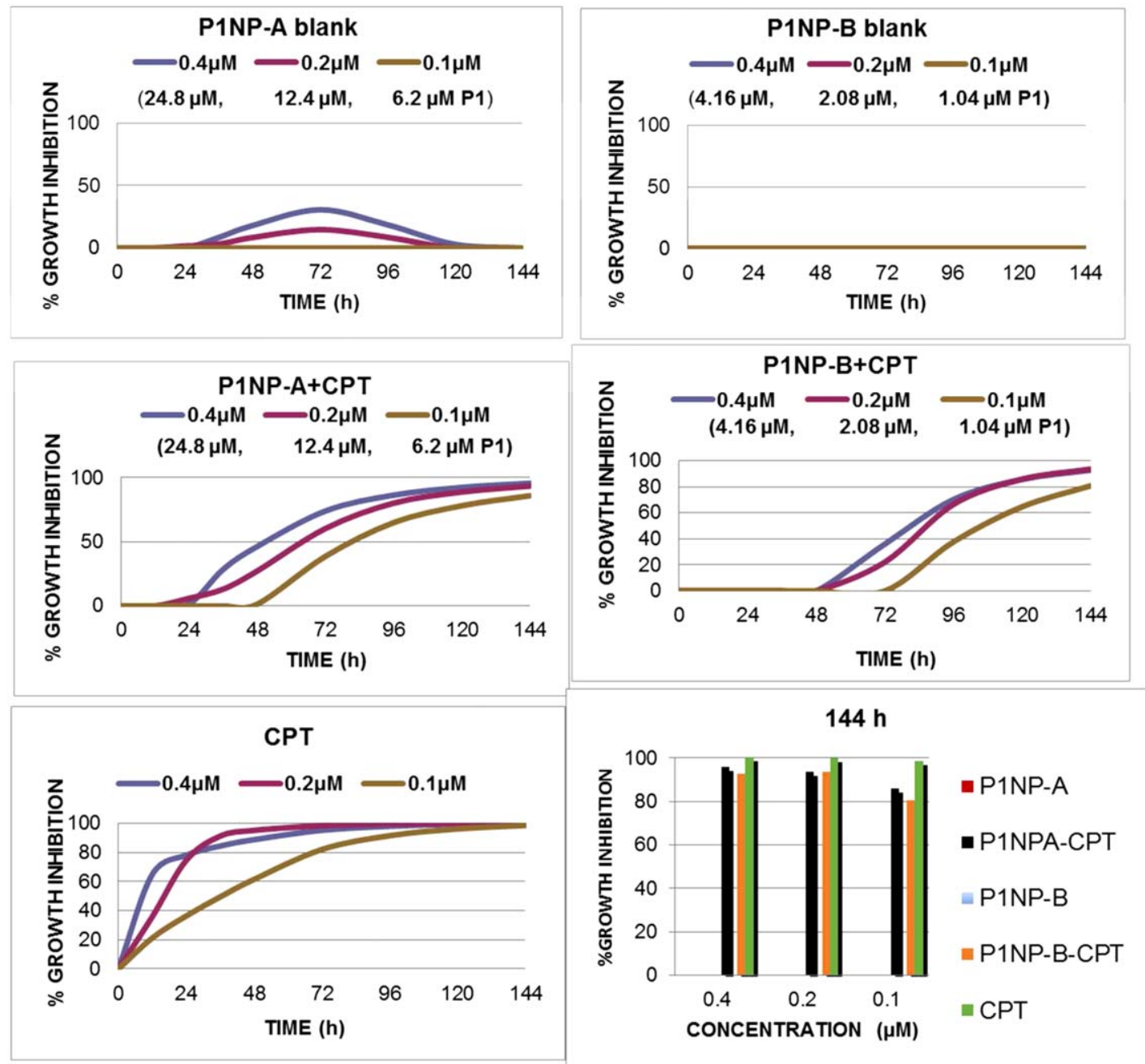

FIGURE 7 Real-time growth inhibitory effect of loaded and blank P1NPs with camptothecin on the human liver (Huh7) cancer cell line were determined by RT-CES. The full profiles of the CPT, P1NP, P1NP-A-CPT and P1NP-B-CPT exposed cells over $144 \mathrm{~h}$ duration. The concentrations are based on CPT concentrations but in brackets the concentrations of nanoparticles were also given. $(0.1,02,04 \mu \mathrm{M}$ CPT concentrations for 1:62 CPT/NP ratios correspond to 6.2, 12.4, $24.8 \mu \mathrm{M}$ NP and for 1:10.4 CPT/NP ratios, 1.04, $2.08,4.16 \mu \mathrm{M} N \mathrm{~N}$ concentrations, respectively). The experiments were conducted in triplicate. [Color figure can be viewed in the online issue, which is available at wileyonlinelibrary.com.]

an efficient cellular internalization. Nuclei were stained with blue emitting Hoechst dye. The image of cells treated with P1NP-A-CPT (with CPT concentration of $0.1 \mu \mathrm{M}$ ) taken after $24 \mathrm{~h}$ incubation show the perinuclear accumulation of redemitting nanoparticles (Supporting Information Fig. S21).

In the light of similar experiments in the literature ${ }^{12,24-26}$ we suggest that NPs and the drug-loaded NPs might be internalized by cells through endocytosis and enriched in intracellular compartments, e.g., cytosolic vesicles and/or endosomes/lysosomes; however, further studies are needed for understanding whether they are differentially targeted into compartments.

\section{CONCLUSIONS}

We have reported the preparation of $\mathrm{pH}$-sensitive, nearinfrared emitting water dispersible conjugated polymer nanoparticles. The nanoparticle dispersions are stable in water over a month without forming any aggregates as well as stable in various biological media. These nanoparticles could be loaded with hydrophobic anticancer drugs with high loading efficiency for drug delivery and cellular imaging. The results indicate that these nanoparticles are promising as vehicles for image-guided, $\mathrm{pH}$ triggered release of anticancer drugs. Currently the work regarding in vivo applications of this system is underway.

\section{ACKNOWLEDGMENTS}

We acknowledge TUBITAK-TBAG 112 T704 and COST Action TD1004 (Theragnostics Imaging and Therapy: An Action to Develop Novel Nanosized Systems for Imaging-Guided Drug Delivery). 


\section{REFERENCES AND NOTES}

1 K.Y. Choi, G. Liu, S. Lee, X. Chen, Nanoscale 2012, 4, 330342.

2 J. Xie, S. Lee, X. Chen, X. Adv. Drug Deliv. Rev. 2010, 62, 1064-1079.

3 L. Chou, K. Ming, W. C. W. Chan, Chem. Soc. Rev. 2011, 40, 233-245.

4 Z. Cheng, A. Al Zaki, J. Z. Hui, V. R. Muzykantov, A. Tsourkas, Science 2012, 338, 903-910.

5 M. Elsabahy, K. L. Wooley, Chem. Soc. Rev. 2012, 41, 25452561.

6 C.-M. J. Hu, R. H. Fang, B. T. Luk, L. Zhang, Nanoscale 2014, 6, 65-75.

7 N. Kamaly, Z. Xiao, P. M. Valencia, A. F. R. Moreno, O. C. Farokhzad, Chem. Soc. Rev. 2012, 41, 2971-3010.

8 S. Nowag, R. Haag, Angew. Chem. Int. Ed. 2014, 53, 49-51.

9 S. Mura, J. Nicolas, P. Couvreur, Nat. Mater. 2013, 12, 9911003.

10 G.-Y. Liu, L. Ping Lv, C.-J. Chen, X.-S. Liu, X.-F. Hu, J. Ji, Soft Matter 2011, 7, 6629.

11 W. Gao, J. M. Chan, O. C. Farokhzad, Mol. Pharmaceutics 2010, 7, 1913-1920.

12 J. R. Casey, S. Grinstein, J. Orlowski, Nat. Rev. Mol. Cell. Biol. 2010, 11, 50-61.

13 R. Alford, M. Ogawa, P. L. Choyke, H. Kobayashi, Mol. Biol. Syst. 2009, 5, 1279-1291.

14 Y. Wang, K. Zhou, G. Huang, C. Hensley, X. Huang, X. Ma, T. Zhao, B. D. Sumer, R. J. DeBerardinis, J. Gao, Nat. Mater. 2014, 13, 204-212.

15 J. A. Barreto, W. O'Malley, M. Kubeil, B. Graham, H. Stephan, L. Spiccia, Adv. Mater. 2011, 23, H18-H40.

16 B. N. G. Giepmans, S. R. Adams, M. H. Ellisman, R. Y. Tsien, Science 2006, 312, 217.

17 P. Zrazhevskiy, M. Sena, X. Gao, Chem. Soc. Rev. 2010, 39, 4326-4354

18 Yan, J. L.; Estevez, M. C.; Smith, J. E.; Wang, K. M.; He, X. X.; Wang, L.; Tan, W. H. Nano Today 2007, 2, 44-50.

19 D. Tuncel, H. V. Demir, Nanoscale 2010, 2, 484-494.

20 I. O. Ozel, T. Ozel, H. V. Demir, D. Tuncel, Opt. Express 2010, 18, 670-684.

21 E. J. Park, T. Erdem, V. Ibrahimova, S. Nizamoglu, H. V. Demir, D. Tuncel, ACS Nano 2011, 5, 2483-2492.

22 V. Ibrahimova, S. Ekiz, O. Gezici, D. Tuncel, Polym. Chem. 2011, 2, 2818-2824.

23 J. Pecher, S. Mecking, Chem. Rev. 2010, 110, 6260-6279.

24 C. Wu, D. T. Chiu, Angew. Chem. Int. Ed. 2013, 52, 30863109.

25 N.A. A. Rahim, W. McDaniel, K. Bardon, S. Srinivasan, V. Vickerman, P. T. C. So, J.H. Moon, Adv. Mater. 2009, 21, 34923496.
26 P. Howes, R. Thorogate, M. Green, S. Jickells, B. Daniel Chem. Commun. 2009, 2490-2492.

27 A. Kaeser, A. P. H. J. Schenning, Adv. Mater. 2010, 22, 2985-2997.

28 I. Fischer, K. Petkau-Milroy, Y. L. Dorland, A. P. H. J. Schenning, L. Brunsveld, Chem. Eur. J. 2013, 19, 16646-16650.

29 P. Howes, M. Green, D. Parker, G. Varma, M. Kallumadil, M. Hughes, A. Warley, A. Brain, R. Botnar, J. Am. Chem. Soc. 2010, 132, 9833.

30 P. Howes, M. Green, J. Levitt, K. Suhling, M. Hughes, J. Am. Chem. Soc. 2010, 132, 3989.

31 K. Pu, A. J. Shuhendler, J. V. Jokerst, J. Mei, S. S. Gambhir, Z. Bao, J. Rao, Nat. Nanotechnol. 2014, 9, 233-239.

32 L. Feng, C. Zhu, H. Yuan, L. Liu, F. Lva, S. Wang, Chem. Soc. Rev. 2013, 42, 6620-6633.

33 C. F. Wu, S. J. Hansen, Q. O. Hou, J. B. Yu, M. Zeigler, Y. H. Jin, D. R. Burnham, J. McNeill, J. M. Olson, D. T. Chiu, Angew. Chem. Int. Ed. 2011, 50, 3430-3434.

34 X. Wang, F. He, L. Li, H. Wang, R. Yan, L. Li, ACS Appl. Mater. Interfaces 2013, 5, 5700-5708.

35 X. L. Feng, F. T. Lv, L. B. Liu, H. W. Tang, C. F. Xing, Q. O. Yang, S. Wang, ACS Appl. Mater. Interfaces 2010, 2, 24292435.

36 H. Gong, L. Cheng, J. Xiang, H. Xu, L. Feng, X. Shi, Z. Liu, Adv. Funct. Mater. 2013, 23, 6059-6067.

37 O. Gezici, I. Durmaz, E. Bilget Guven, O. Unal, A. Ozgun, R. Cetin-Atalay, D. Tuncel, RSC Adv. 2014, 4, 1302-1309.

38 S. Binauld, M. H. Stenzel, Chem. Commun. 2013, 49, 2082 2102.

39 A.W. Jackson, D. A. Fulton, Polym. Chem. 2013, 4, 31-45.

$40 \mathrm{~J}$. Pennakalathil, E. Jahja, E. S. Özdemir, Ö. Konu, D. Tuncel, Biomacromolecules 2014, 15, 3366-3374.

41 J. Geng, Z. Zhu, W. Qin, L. Ma, Y. Hu, G. G. Gurzadyan, B. Z. Tang, B. Liu, Nanoscale 2014, 6, 939.

42 J. Liu, G. Feng, D. Ding, B. Liu, Polym. Chem. 2013, 4, 43264334.

43 Z. Guo, S. Park, J. Yoon, I. Shin, Chem. Soc. Rev. 2014, 43, $16-29$.

44 A. P. Griset, H. Colby, Y. L. Colson, M. W. Grinstaff, Nanoscale 2013, 5, 3496-3504.

45 A. P. Griset, J. Walpole, R. Liu, A. Gaffey, Y. L. Colson, M. W. Grinstaff, J. Am. Chem. Soc. 2009, 131, 2469-2471.

46 B. Valeur, Molecular Fluorescence: Principles and Applications; Wiley-VCH: Weinheim, 2002.

47 L. Otero-Gonzalez, R. Sierra-Alvarez, S. Boitano, Jim A. Field, Environ. Sci. Technol. 2012, 46, 10271-10278.

48 K. Solly, X. B. Wang, X. Xu, B. Strulovici, W. Zheng, Assay Drug Dev. Technol. 2004, 2, 363-372. 